\title{
RESERVOIR PERFORMANCE ANALYSIS USING MATERIAL BALANCE METHOD IN GAS FIELD
}

\author{
Indah Widiyaningsih $^{1 *}$, Panca Suci Widiantoro ${ }^{2)}$, Suwardi $^{3)}$, Riska Fitri Nurul Karimah ${ }^{4}$ \\ 1,3,4) Department of Petroleum Engineering, Faculity of Mineral Technology, UPN "Veteran” Yogyakarta \\ Jl. SWK 104 Yogyakarta 55283 \\ 2) Akamigas Balongan, Jl. Soekarno Hatta, Pekandangan, Indramayu, Jawa Barat 45216 \\ * corresponding e-mail: indahwidiyaningsih@upnyk.ac.id
}

\begin{abstract}
The RF reservoir is a dry gas reservoir located in Northeast java offshore that has been produced since 2018. The RF reservoir has produced 2 wells with cumulative production until December 2019 is 31.83 BSCF. In January 2018 the gas production rate from the two wells was 36 MMSCFD and the reservoir pressure at the beginning of production was 2449.5 psia, peak production occurred in April 2019 with a gas flow rate of 98 MMSCFD but in December 2019 the gas production rate from both wells decreased to 30 MMSCFD with reservoir pressure decreased to 1607.8 psia. Changes in gas flow rate and pressure in the RF reservoir will affect changes in reservoir performance, so it is necessary to analyze reservoir performance to determine reservoir performance in the future with the material balance method. Based on the results the initial gas in place (IGIP) is $80.08 \mathrm{BSCF}$. The drive mechanism worked on the RF reservoir until December 2019 was a depletion drive with a recovery factor up to $88 \%$ and a current recovery factor (CRF) is $40 \%$. The remaining gas reserves in December 2019 is 39 BSCF and the reservoir will be made a production prediction until December 2032. Based on production predictions of the four scenarios, scenario 2 was chosen as the best scenario to develop the RF reservoir with a cumulative production is $66.1 \mathrm{BSCF}$ and a recovery factor of $82.6 \%$.
\end{abstract}

Keywords: gas reservoir; material balance; reservoir performance

\section{INTRODUCTION}

The RF gas reservoir in the NK field is in the northeast java offshore and began to be explored in 2018. The RF reservoir is in a kujung formation with carbonate lithology. Based on the data from the PVT analysis, it is indicated that the RF reservoir is classified as a dry gas reservoir with a gas gravity of 0.6 , and a reservoir temperature of $220^{\circ} \mathrm{F}$. Reservoir RF has produced 2 wells, namely RF-1 and RF-2 with cumulative production until December 2019 is 31.83 BSCF.

Gas production that is carried out continuously causes a decrease in the rate of gas production and reservoir pressure. At the beginning of production, namely January 2018 the gas production rate from the two wells was 36 MMSCFD, and the reservoir pressure at the beginning of production was 2449.5 psia, peak production occurred in April 2019 with a gas flow rate of 98 MMSCFD but overtime in December 2019 the gas production rate from both wells decreased to $30 \mathrm{MMSCFD}$ with reservoir pressure decreased to 1607.8 psia.

Changes in gas flow rate and pressure in the RF reservoir will affect changes in reservoir performance, both static reservoir performance, namely the number of gas reserves, and dynamic reservoir performance, namely daily gas production rate, cumulative production, and reservoir pressure. To determine the performance of the reservoir RF in the future and to find out the strategies that must be carried out in further field development, it is necessary to analyze the performance of the reservoir. The method used in this research is the manual material balance method and uses the IPM-MBAL software. Although the material balance analysis using straight lines allows estimating the original volume of hydrocarbons and the parameters characterizing the aquifer, it is essential to corroborate the estimations by means of the history matching of average reservoir pressure or production (Fuentes-Cruz, Gorgonio., et al.,2021)

\section{MATERIAL BALANCE THEORY}

The material balance method is used to estimate the number of reservoir reserves in a gas field that has been developed, where the production data obtained is quite a lot. The principle of the derivation of the equation is based on the Schiltuis 
equation (1936), which is based on the law of conservation of mass, where the amount of mass in the system is constant or there is a volume balance between cumulative production and reservoir fluid expansion or the net withdrawal of the fluid (produced - inputted) is the sum of the change in the original reservoir fluid volume and the expansion due to pressure drop. There are 3 methods of material balance, namely the P/Z method, the havlena odeh method, and the cole plot method. In this equation; the cumulative withdrawal of reservoir fluids is equated to the combined effects of fluid expansion in the reservoir resulting from a finite pressure drop, pore volume compaction, and water influx (Widiantoro, P.S, et al., 2019). The P/Z method is a straight-line method used to determine the IGIP. The equation for $\mathrm{P} / \mathrm{Z}$ is:

$$
\frac{p}{Z}=\frac{p i}{Z i}-(m) G p
$$

Equation 1 is an equation of a straight line when $(\mathrm{p} / \mathrm{z})$ is plotted versus the cumulative gas production Gp, as shown in Figure 1 (Ahmed, Tarek., 2000). This straight-line relationship is perhaps one of the most widely used relation-ships in gas-reserve determination. The straight-line relationship provides the engineer with the reservoir characteristics:

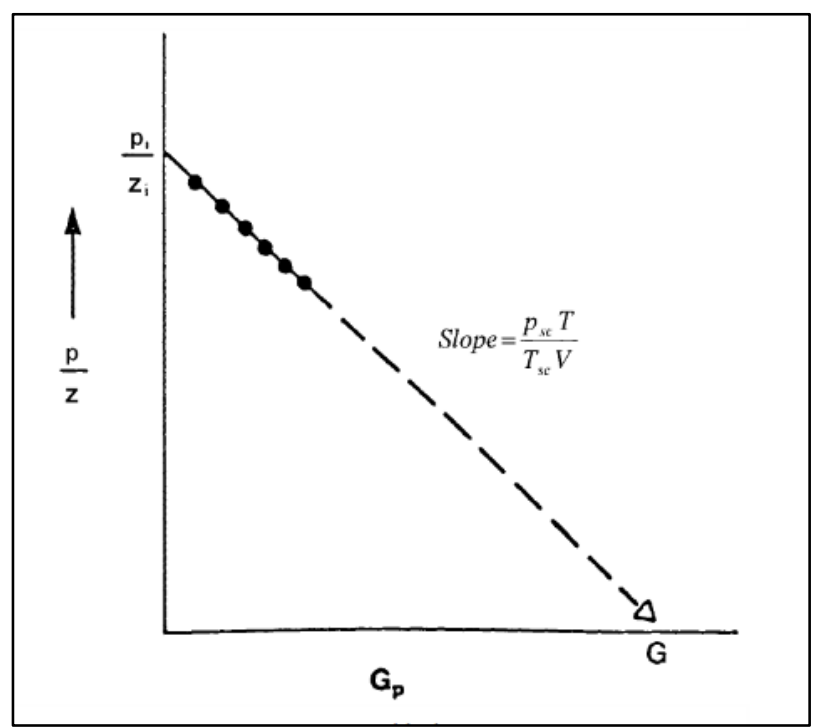

Figure 1. Gas Material Balance Equation

(Ahmed, Tarek., 2000)

Havlena and Odeh (1963) presented techniques for interpreting the material balance equation as a straight line, which makes it easy to apply graphical techniques. In particular, the extrapolation of a straight line allows the prediction of future reservoir performance, while the parameters of the line often are simply related to in-place volumes of water influx. (Widiantoro, P.S et al., 2019). The equation for Havlena and Odeh is:

$$
\frac{F}{E g}=G+\frac{W e B w}{E g}
$$

The F/Eg vs Gp plot yields one of the three defining lines drive mechanism on the reservoir (Ahmed, Tarek.,2006) and will be illustrated in the following Figure 2. 


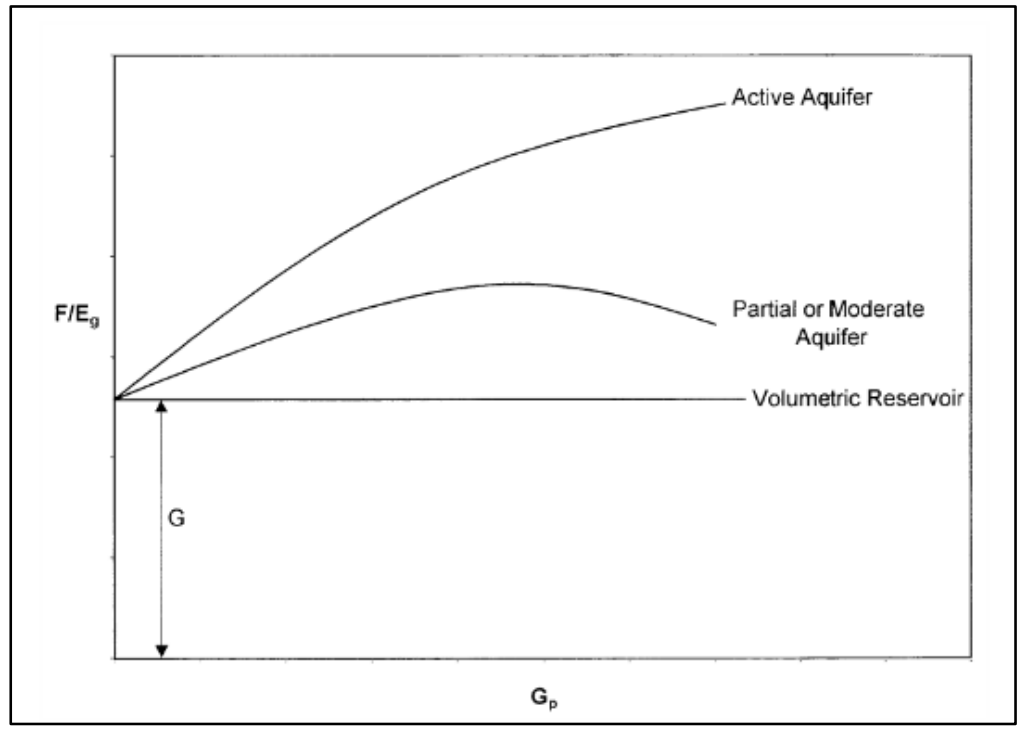

Figure 2. Gas Material Balance Equation

(Ahmed, Tarek., 2000)

The Cole Plot serves to distinguish the gas reservoir drive mechanism, whether it is a water drive or a depletion drive. Cole presented graphical techniques (Widiantoro, P.S et al., 2019), re-arranged the Havlena Odeh equation to become:

$$
\frac{F}{E t}=G+\frac{W e}{E t}
$$

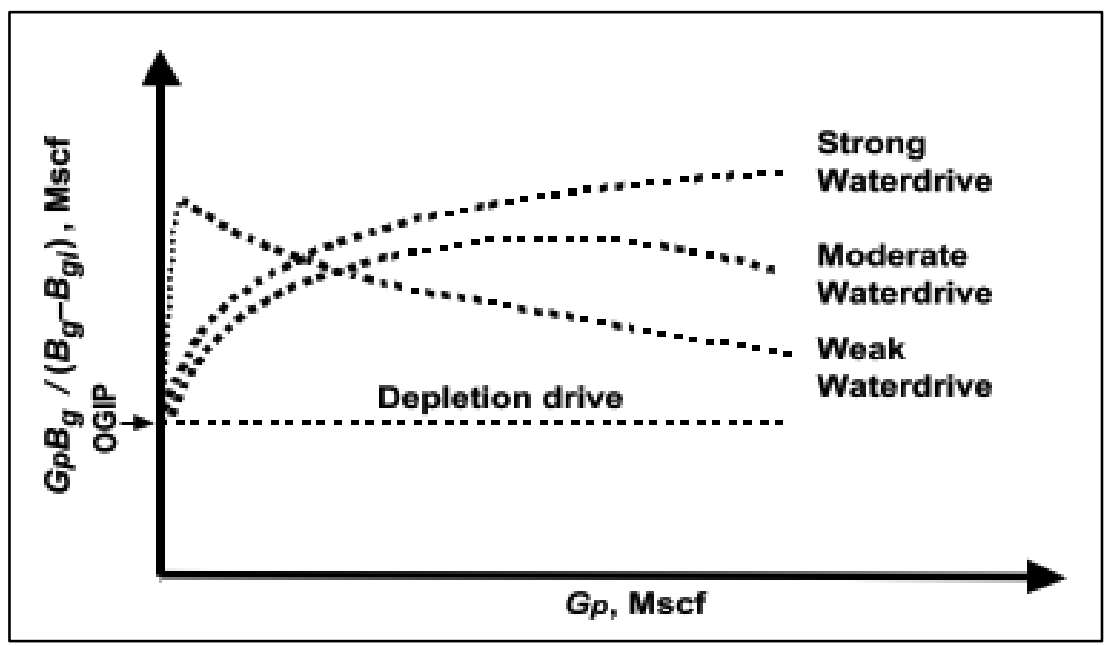

Figure 3. Plot GpBg/(Bg-Bgi) terhadap Gp

(Pletcher J.L., 2002)

Recovery factor $(\mathrm{RF})$ is a percentage that represents the amount of hydrocarbons that can be produced to the surface until it reaches its abandonment pressure. Recovery factor $(\mathrm{RF})$ can be determined by the comparison between the gas produced and the initial gas in place (IGIP). The equation is shown as:

$$
R F=1-\left(\frac{B g i}{B g a}\right) \times 100 \%
$$

If the well has been produced, the current recovery factor can be calculated by:

$$
C R F=\frac{G p}{I G I P} \times 100 \%
$$


Ultimate Recovery is the amount of reserves that can be taken commercially in a reservoir. The relationship between Estimated Ultimate Recovery (EUR), Initial Gas in Place (IGIP), and Recovery Factor (RF) is as follows:

$$
\mathrm{UR}=\mathrm{IGIP} \times \mathrm{RF}
$$

A remaining reserve is the amount of reserve that can still be taken, which is still left in the reservoir and has not been produced. The residual reserve equation is obtained from the difference between ultimate recovery and cumulative production. Ultimate Recovery is the amount of reserves that can be taken commercially in a reservoir. The relationship between Estimated Ultimate Recovery (EUR), Initial Gas in Place (IGIP), and Recovery Factor (RF) is as follows:

$$
\text { Remaining Reserve }(\mathrm{RR})=\mathrm{UR}-\mathrm{Gp}
$$

\section{METHODS}

In this paper, data analysis was carried out using manual calculations and IPM-MBAL software, starting from the calculation of the average reservoir pressure and gas physical properties, calculating the initial gas in place (IGIP), and determining the drive mechanism using 3 material balance methods, namely $\mathrm{P} / \mathrm{Z}$ method, Havlena-Odeh method and Cole plot method. Furthermore, the calculation of the amount of recovery factor and the calculation of the amount of remaining reserve. If it is known the amount of remaining reserve, then a production prediction is made with several scenarios.

1. Performing the Calculation of Physical Properties of Gases

Determination of the physical properties of gases with correlations to calculate the compressibility factor ( $\mathrm{Z}$ Factor) and formation volume factor $(\mathrm{Bg})$.

2. Calculation of Initial Gas in Place (IGIP)

With the availability of production history and pressure history data, the initial gas in place (IGIP) can be calculated using the material balance method.

3. Analyze the Drive Mechanism

The analysis of the driving mechanism was carried out by comparing the material balance methods, namely the P/Z, Havlena Odeh, and Cole-Plot methods. In gas reservoirs, the graph proposed by Cole (1969) is useful to identify a water drive from an adjacent aquifer. The Cole plot consists of plotting the F/Eg group versus Gp, so that data points show trends indicating the drive type (strength) supplied from the adjacent aquifer (Pletcher, J.L., 2002). Thus, a horizontal straight line implies no water drive (volumetric reservoir); when increasing and decreasing trends at the early stage of the curve are observed, a weak drive aquifer is present. If the curve trend gradually increases and shows a slight decrease, then the aquifer drive is moderate. When the trend is continuously increasing, it implies an active (strong) aquifer (Fuentes-Cruz, Gorgonio., et al.,2021).

4. Calculating the Recovery Factor

Calculating the amount of recovery factor is carried out to determine the number of hydrocarbons that can be produced to the surface until it reaches its abandonment pressure and determines the amount of hydrocarbons that have been produced to date.

5. Calculating the Amount of Remaining Reserve

Knowing the amount of the remaining reservoir is very important to know the amount of reserves that can still be taken, which is still left in the reservoir and has not been produced.

6. Doing Production Prediction

After calculating the amount of the remaining reserve, the next step is to make a production prediction (forecast) following the agreed contract.

Figure 4 shows a detailed flowchart of this research.

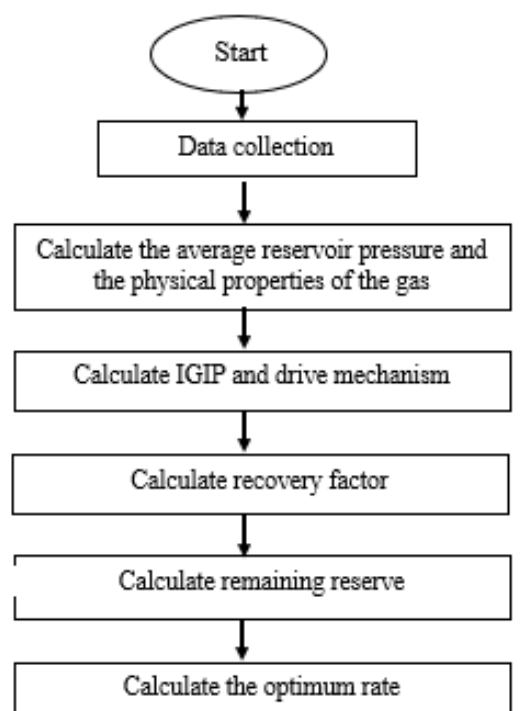


Figure 7. Flowchart of Reservoir Performance Analysis

\section{RESULTS AND DISCUSSION}

This chapter will explain the calculations carried out to analyze the performance of the RF gas reservoir in the NK field. This study uses the manual material balance method and uses the IPM-MBAL simulator to determine the performance of the RF reservoir.

\subsection{Average Reservoir Pressure}

The average reservoir pressure prediction is based on reservoir pressure data for each production well against production time as shown in the figure and cumulative production as shown in the Figure 1. Then from the plot of pressure on cumulative production. Based on the historical data plot of reservoir pressure vs. cumulative production, the trendline equation $y=-30.507 x+2449.5$ is obtained. Furthermore, the reservoir pressure RF will be calculated on a certain date using the trendline equation with $\mathrm{y}$ being the amount of pressure and $\mathrm{x}$ being the cumulative amount of production that will be included in the equation, so that the results are as shown in the table where it is shown that reservoir pressure starts on January 2018 of 2450 psia has decreased to 1847 psia on March 2019. Based on this average reservoir pressure, the gas compressibility factor (Z Factor) is calculated.

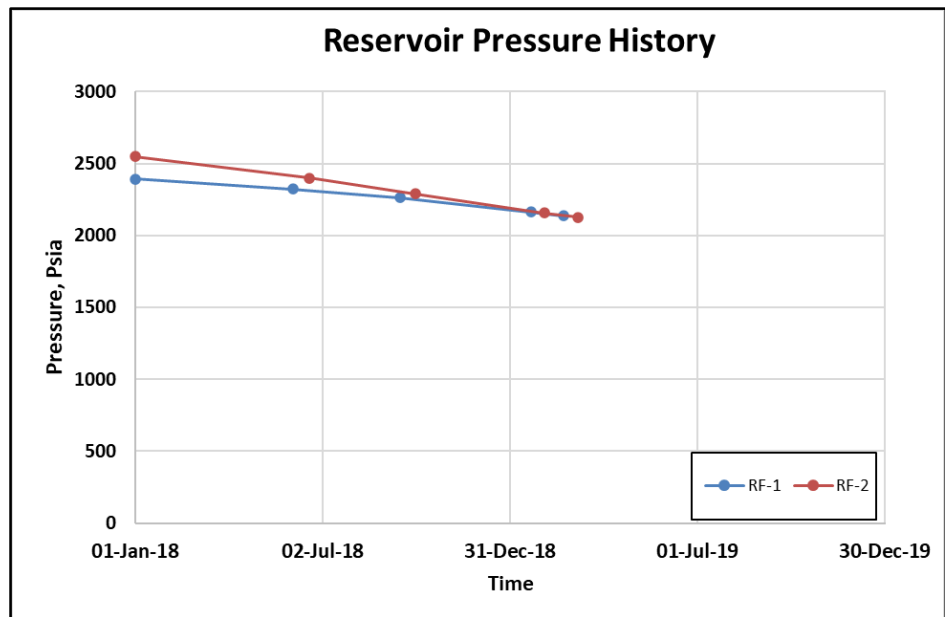


Figure 4. Reservoir Pressure History

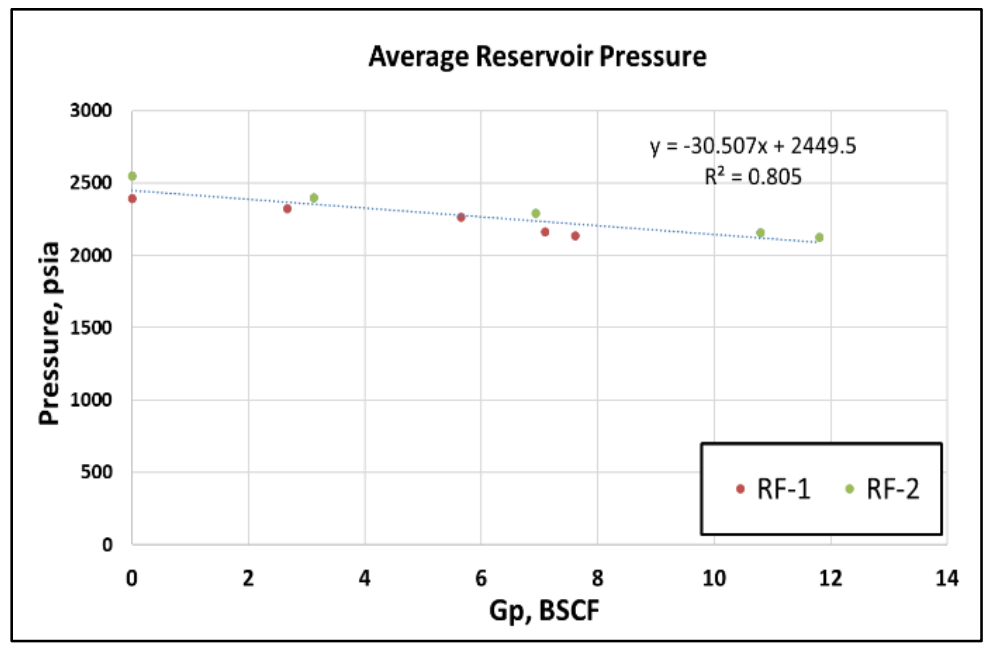

Figure 5. Average Reservoir Pressure

Table 1. Average Reservoir Pressure

\begin{tabular}{cc}
\hline Time & Pressure, psia \\
\hline 01-Jan-2018 & 2450 \\
19-Jun-2018 & 2255 \\
30-Sep-2018 & 2060 \\
20-Jan-2019 & 1915 \\
02-Feb-2019 & 1899 \\
21-Feb-2019 & 1871 \\
07-Mar-2019 & 1847 \\
\hline
\end{tabular}

\subsection{Gas Compressibility (Z Factor) and Gas Volume Factor (Bg)}

The results of the calculation of the gas compressibility factor ( $Z$ Factor) are obtained based on the average reservoir pressure value calculated by the Beggs and Brill correlation (1974) and the calculation of the gas formation volume factor $(\mathrm{Bg})$ uses the real gas equation of state correlation at a reservoir temperature of $220^{\circ} \mathrm{F}$ or $680{ }^{\circ} \mathrm{R}$ and the following results are obtained:

Table 2. Compressibility Factor (Z Factor) and Gas Volume Factor (Bg) Result

\begin{tabular}{lllll}
\hline Time & Pressure, psia & Gp, BSCF & Z Factor & Bg, ft $\mathbf{f t}^{3} / \mathbf{s c f}$ \\
\hline
\end{tabular}




$\begin{array}{lllll}\text { 01-Jan-2018 } & 2450 & 0 & 0.91889 & 0.007219 \\ \text { 19-Jun-2018 } & 2255 & 6.38 & 0.92001 & 0.007852 \\ \text { 30-Sep-2018 } & 2060 & 12.78 & 0.92232 & 0.008617 \\ \text { 20-Jan-2019 } & 1915 & 17.52 & 0.92477 & 0.009294 \\ \text { 02-Feb-2019 } & 1899 & 18.04 & 0.92507 & 0.009373 \\ \text { 21-Feb-2019 } & 1871 & 18.95 & 0.92562 & 0.009518 \\ \text { 07-Mar-2019 } & 1847 & 19.76 & 0.92613 & 0.009651\end{array}$

\subsection{P/Z Method}

In calculating the initial gas in place (IGIP) the material balance P/Z method, the data needed are time data, reservoir pressure, cumulative production, and gas compressibility factor ( $Z$ Factor). The following are the results of calculating the P/Z Method manually and the IPM-MBAL software.

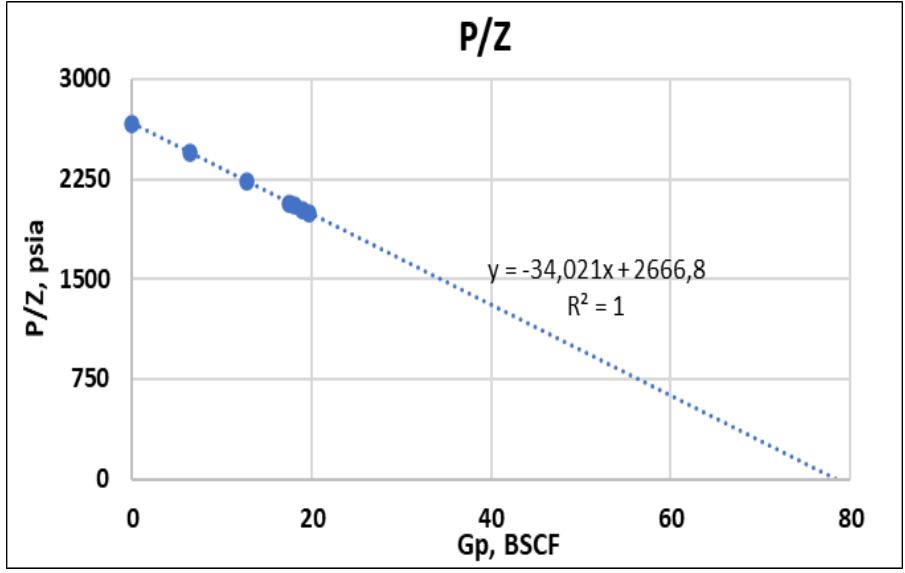

Figure 6. Plot of Cumulative Gas Production (Gp) vs P/Z Manual

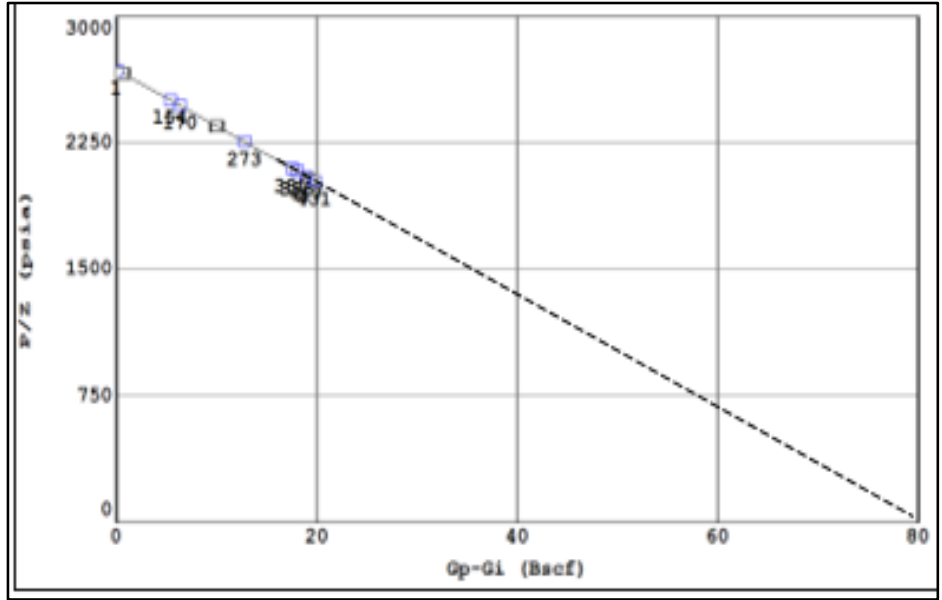

Figure 7. Plot of Cumulative Gas Production (Gp) vs P/Z Software IPM-MBAL

In the $\mathrm{P} / \mathrm{Z}$ material balance method, the initial gas in place (IGIP) reservoir RF is $78.39 \mathrm{BSCF}$, and the initial gas in place (IGIP) using the IPM-MBAL software is $80.08 \mathrm{BSCF}$ and based on graphic analysis formed from the P/Z vs Gp in Figure 
6 and Figure 7 shows that the graph formed is a straight line or there is no deflection which indicates that the drive mechanism that is working is the depletion drive.

\subsection{Havlena Odeh Method}

The steps in determining the amount of initial gas in place (IGIP) and the type of drive mechanism using the HavlenaOdeh method are to prepare the required data, namely cumulative gas production and formation volume factor. The following are the results of calculating the Havlena-Odeh Method manually and the IPM-MBAL software.

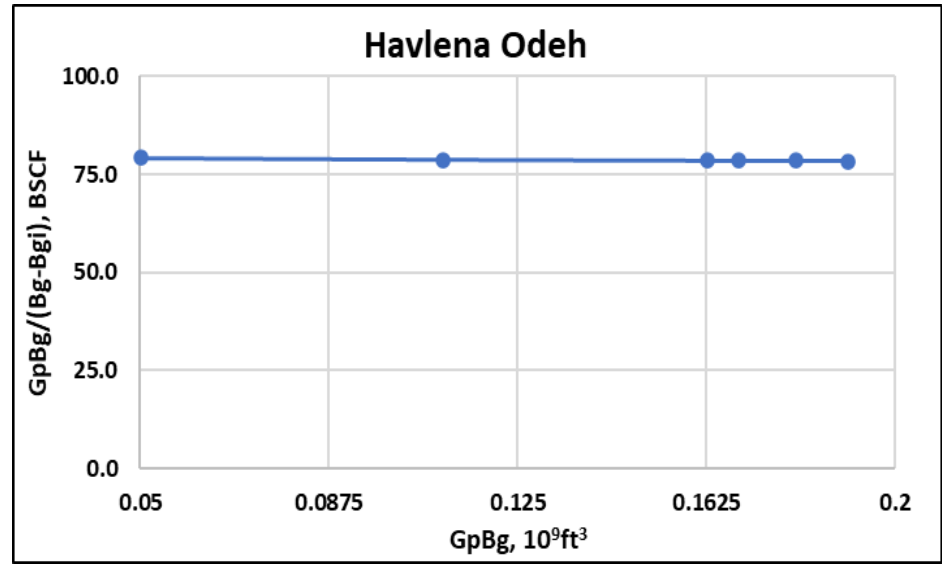

Figure 8. Plot of of GpBg/(Bg-Bgi) vs GpBg Manual

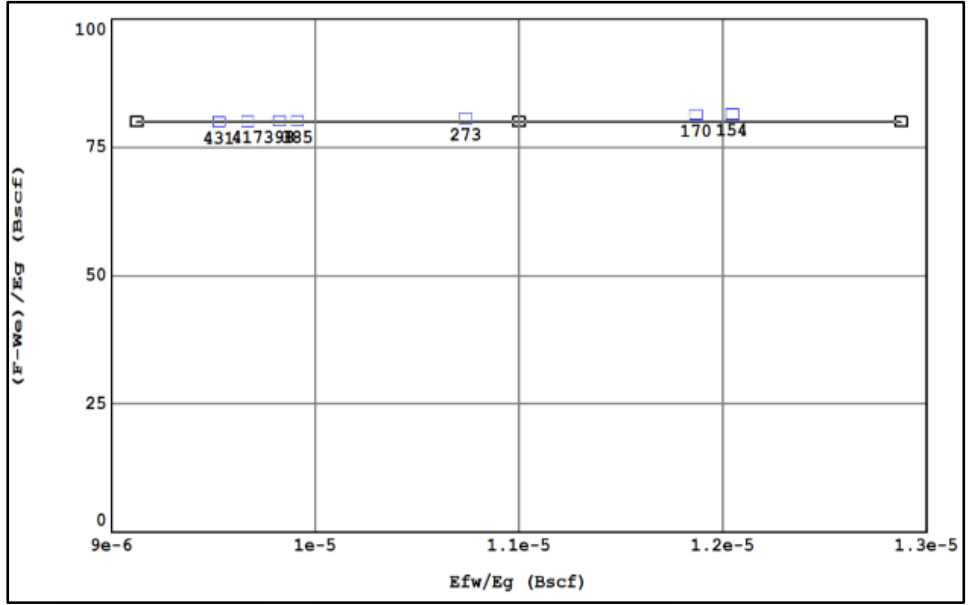

Figure 9. Plot of Plot (F-We)/Eg vs Efw/Eg Software IPM-MBAL

In the havlena odeh method, the initial gas in place (IGIP) reservoir RF is 78.5 BSCF, and the initial gas in place (IGIP) using the IPM-MBAL software is $80.09 \mathrm{BSCF}$ and based on graphic analysis formed from $\mathrm{GpBg} /(\mathrm{Bg}-\mathrm{Bgi}) \mathrm{vs} \mathrm{GpBg}$ and Plot of Plot (F-We)/Eg vs Efw/Eg the in Figure 8 and Figure 9 shows that the graph formed is a straight line or there is no deflection which indicates that the drive mechanism that is working is the depletion drive. 


\subsection{Cole Plot Method}

The calculation of initial gas in place (IGIP) using the Cole Plot material balance method requires cumulative production data, reservoir pressure data, and gas formation volume factor $(\mathrm{Bg})$ at each existing reservoir pressure. This data is then used to determine the value of underground withdrawal $(\mathrm{F})$ and total reservoir expansion (Et) or often described as $\mathrm{GpBg} /(\mathrm{Bg}-\mathrm{Bgi})$ which will later be used to make cumulative F/Et vs gas production $(\mathrm{Gp})$ or $\mathrm{GpBg} /(\mathrm{Bg}-\mathrm{Bgi})$ vs $\mathrm{Gp}$. The following is the calculation result of the Cole Plot material balance method which is calculated manually and using the IPM-MBAL simulator. The following are the results of calculating the Cole Plot Method manually and the IPM-MBAL software.

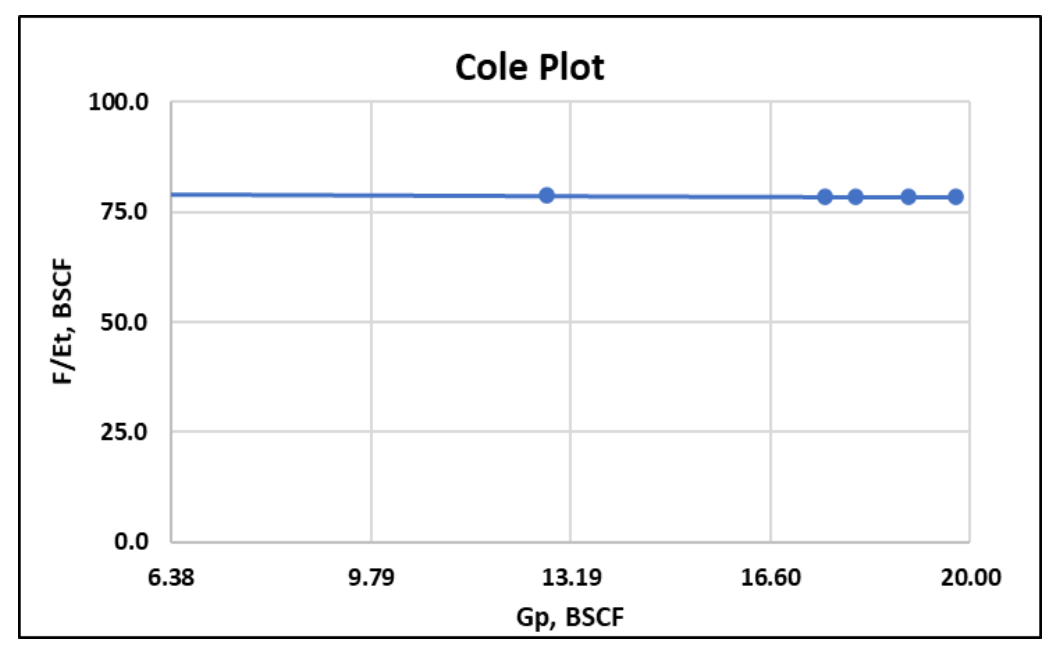

Figure 10. Plot of F/Et vs Gp Manual

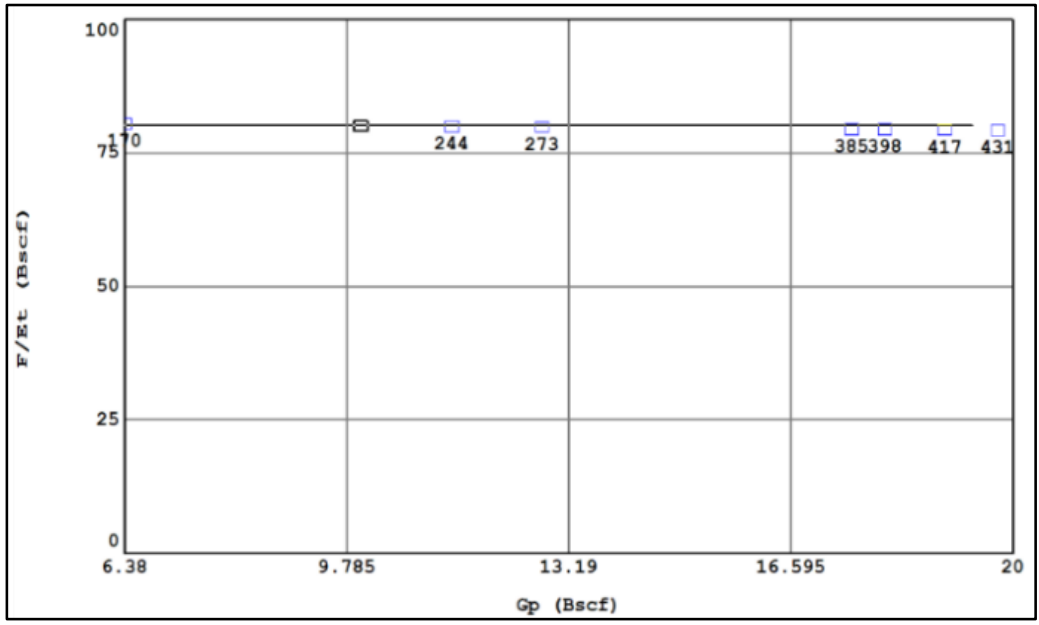

Figure 11. Plot of F/Et vs Gp Software IPM-MBAL 
In the cole plot method, the initial gas in place (IGIP) reservoir RF is $79.2 \mathrm{BSCF}$, and the initial gas in place (IGIP) using the IPM-MBAL software is 80.09 BSCF and based on graphic analysis formed from F/Et vs Gp the in Figure $\mathbf{1 0}$ and Figure 11 shows that the graph formed is a straight line or there is no deflection which indicates that the drive mechanism working is the depletion drive.

Then the drive index analysis of the IPM-MBAL simulation results is carried out which can be seen in Figure 12 it can be analyzed that there is Fluid Expansion (Depletion Drive) as a drive mechanism at the beginning of production to date based on available data, namely January 2018 - December 2019.

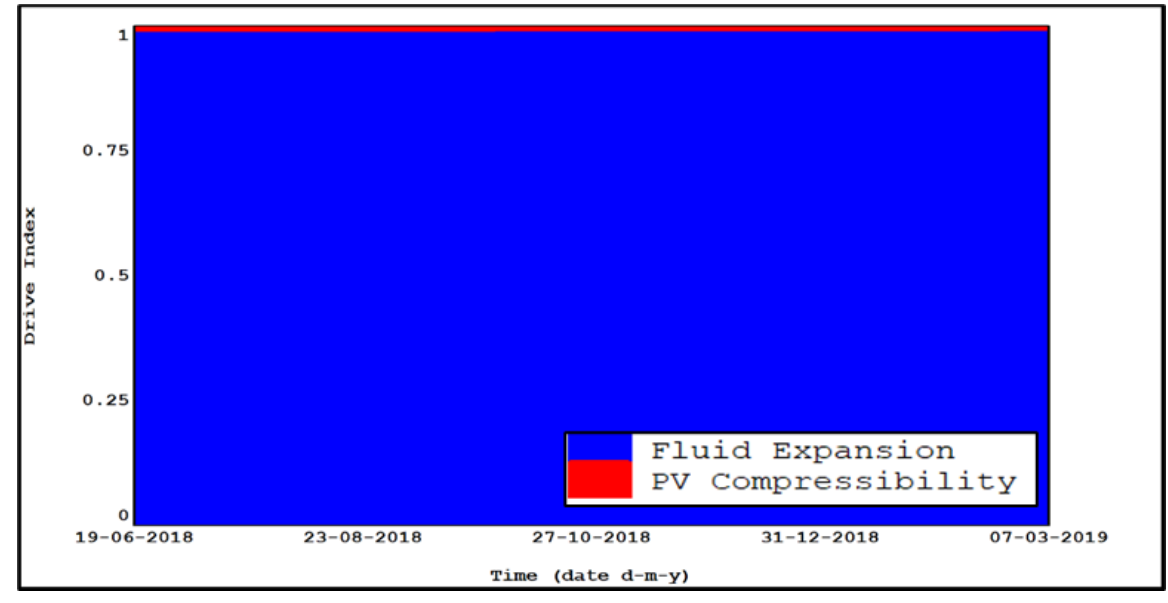

Figure 12. Drive Index RF Reservoir

Based on the results of calculations and analysis of the three methods of material balance and drive index on the IPMMBAL simulator, it can be seen that the drive mechanism that works on the RF reservoir is a depletion drive so the material balance method that can be used to estimate the amount of initial gas inplace (IGIP) is the method material balance $\mathrm{P} / \mathrm{Z}$ because the $\mathrm{P} / \mathrm{Z}$ method is more representative of reservoir gas depletion with no deflection on the $\mathrm{P} / \mathrm{Z}$ line plot. So that the initial gas in place (IGIP) reservoir RF is estimated at $80.08 \mathrm{BSCF}$.

\subsection{Recovery Factor and Remaining Reserve}

The calculation of the recovery factor (RF) for the RF reservoir begins with calculating the formation volume factor at an initial pressure of 2450 psia and a formation volume factor at an abandonment pressure of 300 psia. Based on equation (4), the amount of recovery factor for reservoir RF is $88 \%$, and based on equation (5), the magnitude of the current recovery factor is $40 \%$. From the calculation, it is found that the recovery factor (RF) up to the abandonment pressure is $88 \%$, this is following the provisions where if the drive mechanism that works on the reservoir is a depletion drive, the recovery factor is around $80-90 \%$.

With a recovery factor value of $88 \%$ and initial gas in place value of 80.08 BSCF, based on equation (6), the ultimate recovery is $70.83 \mathrm{BSCF}$ and the amount of remaining reserve based on equation (7) is $39 \mathrm{BSCF}$.

\subsection{Production Prediction}

The RF reservoir RF is charged to produce gas until December 31, 2032, it is necessary to calculate the gas flow rate that can be produced by reservoir RF. The gas flow rate calculation is done using the conventional method of gas deliverability test analysis on the IPM-MBAL simulator. The steps for data input on the IPM-MBAL simulator with reservoir pressure at the end of the production history of 1607.8 psia and it is known that the magnitude of $\mathrm{n}$ is 1 and $\mathrm{C}$ is $0.02001 \mathrm{Mscf} / \mathrm{day} / \mathrm{psi} 2$ so that the deliverability curve is obtained as follows:

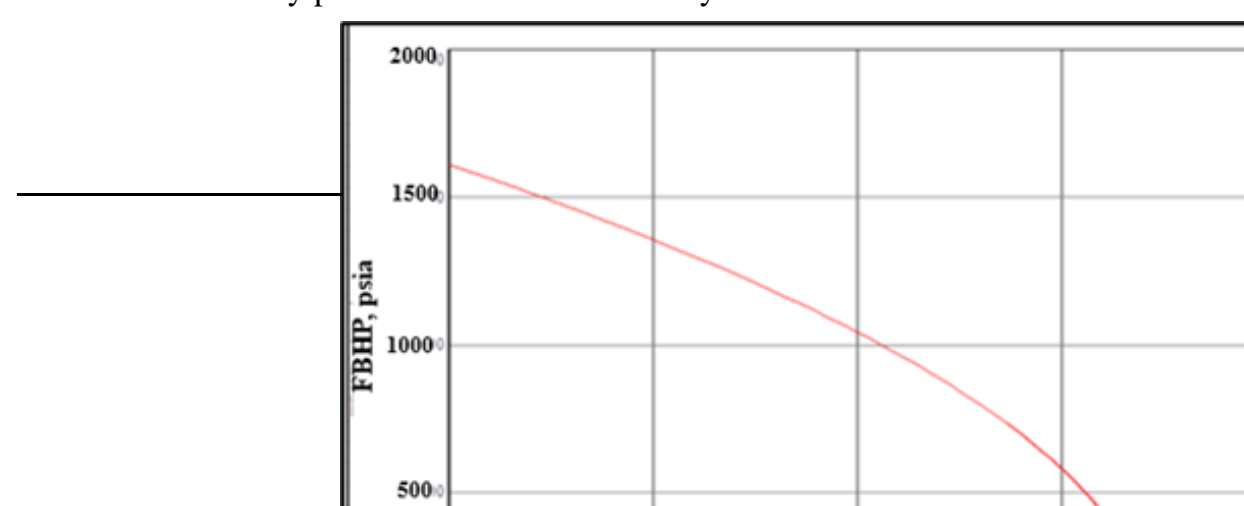


Figure 13. RF-1 and RF-2 Well Deliverability Curves

Based on the deliverability curve above, the absolute open flow (AOF) is 52 MMSCFD and the optimum gas flow rate is $30-60 \%$ of the AOF, which is 15 MMSCFD to 36 MMSCFD.

Then the reservoir RF will be made a production prediction until December 31, 2032 with a gas flow rate constraint of 15 MMSCFD per well or 30 MMSCFD with 2 wells according to the previous gas flow rate. Production prediction results as follows:

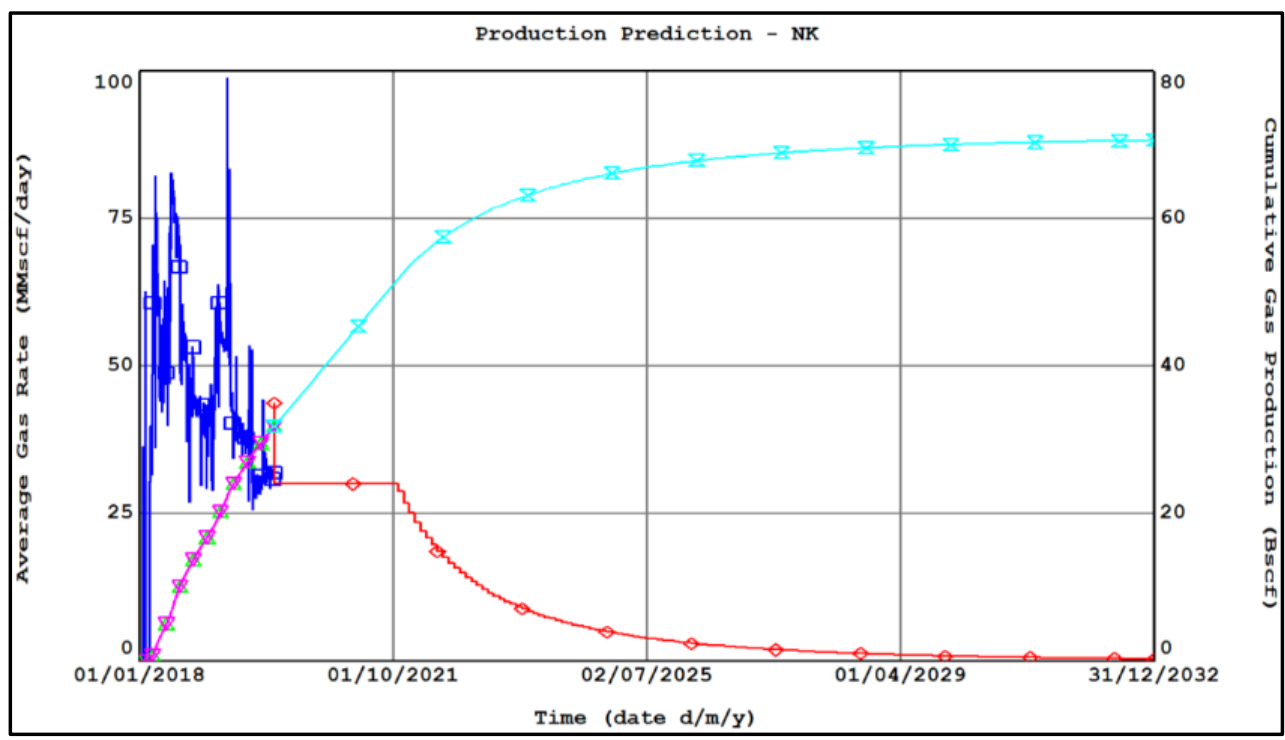

Figure 14. Result of Production Rate and Cumulative Production @ Constraint 30 MMSCFD

After making a production prediction with a gas flow rate constraint of 15 MMSCFD per well as shown in Figure 14, the RF reservoir is only able to produce constant production of 30 MMSCFD until October 28, 2021 with cumulative production $(\mathrm{Gp})$ at the end of plateau of $51.8 \mathrm{BSCF}$ and recovery factor of $65 \%$, then a production prediction is made with several scenarios, namely scenario 2 , scenario 3 and scenario 4 to find out in what scenario the reservoir RF can produce the highest recovery factor $(\mathrm{RF})$.

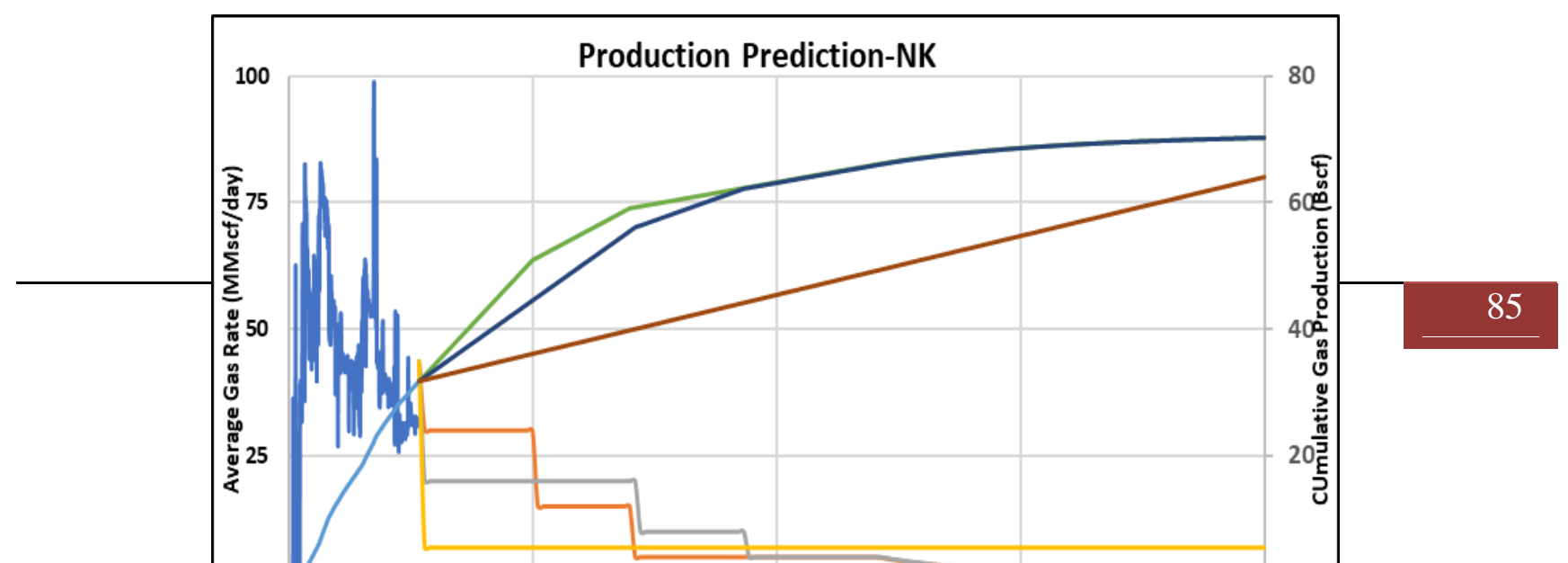


Figure 15. Result of Production Rate and Cumulative Production

Table 3. Scenario Comparison Results Figure 8. Results of Comparison of Production Rates for Each Scenario

\begin{tabular}{ccccccc}
\hline Scenario & $\begin{array}{c}\text { Gas Rate, } \\
\text { MMSCFD }\end{array}$ & $\begin{array}{c}\text { Start } \\
\text { Plateau }\end{array}$ & $\begin{array}{c}\text { End of } \\
\text { Plateau }\end{array}$ & $\begin{array}{c}\text { Plateau } \\
\text { Year }\end{array}$ & $\begin{array}{c}\text { Gp, } \\
\text { BSCF }\end{array}$ & RF \\
\hline Scenario 1 & 30 & 01-Jan-2018 & 28-Oct-2021 & 1.8 & 51.8 & $65 \%$ \\
Scenario 2 & 30 & 01-Jan-2018 & 28-Oct-2021 & 7 & 66.1 & $82.6 \%$ \\
& 15 & 28-Oct-2021 & 28-Mar-2023 & & & \\
Scenario 3 & 5 & 28-Mar-2023 & 28-Dec-2026 & & & \\
& 20 & 01-Jan-2020 & 28-Apr-2023 & 7.1 & 65.8 & $82 \%$ \\
Scenario 4 & 10 & 28-Apr-2023 & 28-Dec-2024 & & & \\
& 5 & 28-Dec-2024 & 28-Jan-2027 & & & \\
& 6.8 & 01-Jan-2020 & 31-Dec-2032 & 13 & 64 & \\
\hline
\end{tabular}

Based on the results of the production prediction in Table 3 it can be seen that in scenario 2 the RF reservoir can produce constantly with a gas flow rate of 30 MMSCFD until October 28, 2021 then continue with a gas flow rate of 15 MMSCFD capable of constant production until March 28, 2023 and continue with a gas flow rate of 5 MMSCFD capable of constant production until December 28, 2026 with cumulative production of $66.1 \mathrm{BSCF}$.

In scenario 3 reservoir RF can produce constantly with a gas flow rate of 20 MMSCFD until April 28, 2023 then continued with a gas flow rate of 10 MMSCFD capable of constant production until December 28, 2024 and continued with a gas flow rate of 5 MMSCFD capable of constant production. until January 28, 2027 with cumulative production of 65.8 BSCF.

In scenario 4 with a gas flow rate of 6.8 MMSCFD the RF reservoir is capable of constant production until December 31 , 2032 or until the end of the contract and the cumulative gas production is $64 \mathrm{BSCF}$.

In this study scenario 2 was chosen as the best scenario for the development of the "NK" field because in scenario 2 the highest recovery factor (RF) was obtained compared to other scenarios, which was $82.6 \%$.

\section{CONCLUSION}


As the result of the study is initial gas in place (IGIP) from RF reservoir amount 80.08 BSCF with the drive mechanism that works until December 31, 2019, is depletion drive. Based on the calculation, it can be seen that the recovery factor up to the abandonment pressure is $88 \%$ and the current recovery factor (CRF) is $40 \%$. With the remaining reserve 39 BSCF, the RF reservoir is capable of producing until December 31, 2032 with a gas flow rate of 30 MMSCFD until October 28, 2021 then continue 15 MMSCFD capable of constant production until March 28, 2023 and continue with a gas flow rate 5 MMSCFD capable of constant production until December 28, 2026 with cumulative production of 66.1 BSCF and recovery factor $82.6 \%$. Changes in gas rate and pressure in the reservoir RF will affect the reservoir performance, namely static and dynamic reservoir performance. Static reservoir performance will affect initial gas in place (IGIP) and remaining reserve, while dynamic reservoir performance will affect the gas rate, cumulative gas production, and reservoir pressure which will affect reservoir performance in the future.

\section{ACKNOWLEDGEMENT}

The authors wish to express their deepest gratitude towards Mrs. Boni Swadesi also respective lecturers for their support and review. Special thanks to the Faculty of Mineral Technology, Petroleum Engineering Department in providing the facilities for this research.

\section{REFERENCES}

Ahmed, Tarek. (2000). Reservoir Engineering Handbook, Second Edition. Texas: Gulf Professional Publishing Company.

Ahmed, Tarek. (2006). Reservoir Engineering Handbook, Third Edition. Texas: Gulf Professional Publishing Company.

Beggs, H Dale. (1984). Gas Production Operations. Tulsa: Oil and Gas Consultants International Inc.

Chaudhry, Amanat U. (2003). Gas Well Testing Handbook. Texas: Gulf Professional Publisihing, Texas

Craft, B.C, and Hawkins, M.F. (1991). Applied Petroleum Reservoir Engineering, Second Edition. Prentice-Hall, Lousiana State University

Dake, L.P. (1994). The Practice of Reservoir Engineering, Revised Edition. Amsterdam: Elvesier.

Fuentes-Cruz, Gorgonio., et al. (2021). Reservoir Performance Analysis Through the Material Balance Equation: An Integrated Review Based on Field Examples. Journal of Petroleum Science and Engineering 208 (2022) 109377

Ikoku, Chi.U. (1984). Natural Gas Reservoir Engineering. Florida: Krieger Publishing Company.

Pletcher, J L. (2002). Improvements to Reservoir Material-Balance Methods. SPE, Marathon Oil Co.

Smith, C.R., Tracy, G.W., Farrar, R.L. (1992). Applied Reservoir Engineering. Oklahoma: OGCI Publication

Sugiyono. (2017). Metode Penelitian Kuantitatif, Kualitatif, dan R\&D. Bandung: Alfabeta, CV.

Widiantoro, P,.S.et al (2019). Gas Material Balance Analysis from The Early to The Late Time Production of T Field. Indonesian Petroleum Association Forty-Third Annual Convention \& Exhibition

Zhang, Miao., Ayala, Luis. (2015). A New Material Balance Equation for the Analysis of Liquid Rich Natural Gas Reservoirs. Society of Petroleum Engineers. SPE-175081-MS 